\title{
NEW SOLUTION OF SHAKER's SUPPORTING STRUCTURE INTENDED TO RAILWAY BRIDGES TESTING
}

\author{
SKOCZYNSKI, W.; KRZYZANOWSKI, J. \& BIEN, J.
}

Abstract: The dynamic performances of railway bridges structures under the train loads come into more and more prominence with development of high-speed railways being built in the world. It forces to develop some methods to test them. The aim of this study was to develop a new shaker's supporting structure to inspect railway bridges dynamic parameters and perform some dynamic tests for shaker - frame dynamometers structure. A special frame transferring the excitations to the rails was designed and produced. Then it was tested together with the shaker. Some results of laboratory tests were presented. The shaker together with a new construction of the supporting frame, adopted to its fastening to rails, fulfill all the functional assumptions, i.e. they allow to: permanently measure components of the excitation forces during the railway bridge inspections, temporarily attach the wheel system for the transport purposes and raise/lower the system for attaching/detaching wheels and fastening/removing dynamometers. The shaker with the supporting system allows obtaining an excitation force with a stable frequency and the amplitude deviations no larger then 5\% of nominal value. The deviations get smaller when the excitation frequency and resulting excitation force increase.

Key words: inertial shaker, construction, railway bridges, dynamic behaviour, testing
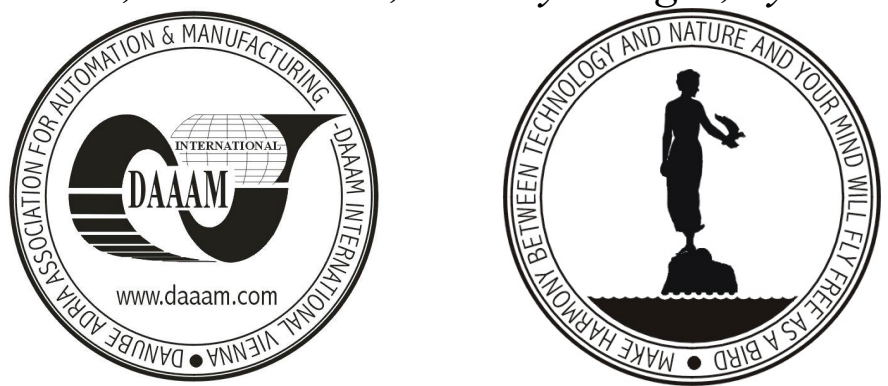

Authors' data: Dr.Sc. Skoczynski W.[aclaw], Prof. Dr. Krzyzanowski J.[ozef], Dr.Sc. Bien J.[an], waclaw.skoczynski@pwr.wroc.pl, jozef.krzyzanowski@pwr.wroc.pl, jan.bien@pwr.wroc.pl, Wroclaw University of Technology, Wroclaw, Poland

This Publication has to be referred as: Skoczynski, W.; Krzyzanowski, J. \& Bien, J. (2006). New Solution of Shaker's Supporting Structure Intended to Railway Bridges Testing, Chapter 46 in DAAAM International Scientific Book 2006, B. Katalinic (Ed.), Published by DAAAM International, ISBN 3-901509-47-X, ISSN 1726-9687, Vienna, Austria

DOI: $10.2507 /$ daaam.scibook.2006.46 